\title{
María Ángeles MAESO, Basura mundi, Madrid, Huerga y Fierro, 2008, 58 pp.
}

En su anterior libro, Vamos, vemos (2004), María Ángeles Maeso (Soria, 1955), exponía una memoria rural, campesina, revelada y desvelada -de desvelo- en un lenguaje jugoso y renovado, entre insomne y consciente, crítico. En este último, Basura mundi, el lenguaje se mantiene básicamente en la misma línea, reforzándose por ambos extremos: el del desconsuelo, el de la ternura. Pero no es ya la memoria de una raíz personal, de una vivencia del pequeño mundo, sino la amarga, hiriente constatación de los desquiciamientos sociales de la globalización. Habla pegada al asfalto de la gran ciudad y al barro y los detritos que ésta expulsa hacia los flancos, donde pierde el nombre. La voz poética no es ahora tanto la voz de la experiencia cuanto la de la conciencia.

El primer acierto es ya el título, que corroborará el resto, es la puerta para adentrarse en un lenguaje dúctil, tierno, irreverente y hermoso que pone cerco a una realidad en llamas que está pidiendo a gritos la palabra urgente que acierte a desvelarla en medio de las mordazas y las corazas del poder. Es dar voz a lo que no la tiene, tales son su insignificancia y su marginación. ¿Cuál es actualmente el "axis mundi" o la "lux mundi"? El discurso oficial, ubicuo, se ha encargado de desplazar y anular el centro y de apagar la luz. Sin humanismo, la deshumanización global, imponente, masificada, sólo deja ver, por más que intente ocultarla con eufemismos o silencios, la basura que engendra.

Hay poesía y dolor en los suburbios. Lo descubre el lenguaje que da cuenta de la belleza dolorida ya en el primer poema: “Un lilo sale por el tejado”. La mirada, el corazón leen con tanta acritud como ternura el paisaje de la miseria y la marginación: en la fealdad provocada socialmente la belleza natural no se arredra y resiste e insiste. El lilo se humaniza en el poema y humaniza el entorno contra toda lógica, y contra toda esperanza. El poeta lo "siente", y lo canta y lo cuenta. Testimonia esa naturaleza "solidaria", a falta de la humana, con vistosas sinestesias: 
Es un lilo dispuesto a todo.

Hace en los charcos

un gran eco su morada sombra.

¡Cómo lo oigo!

La miseria de los suburbios madrileños, el desvalimiento de los más débiles y desocupados, guerra de Irak, la inmigración, el progreso ciego, la deshumanización tecnológica son los temas de esta poesía comprometida del nuevo milenio. Insiste, también, en la dignidad personal, en los bornes que la contienen, al filo de la desesperación. Logra en este sentido poemas de ajustado enfoque, de contenida emotividad, como "Cercanías Renfe", "Mujer con el finiquito en la mano", "Pozo". No menos elocuentes, aunque quizás más despiadados, son los antibelicistas, particularmente en títulos como "Poema urgente para un soldado yanqui" o "El paso de meteco a ciudadano", tan directos, tan incisivos en su estremecida desnudez.

La acusación manifiesta en estos textos es la de la deshumanización de un sistema u orden económico/social/político... mundial que oblitera la realidad de las personas y las sacrifica en aras de la cuantificación y de la eficacia de un progreso, por irracional, injusto. Lingüísticamente, esta despersonalización queda reflejada en varios poemas mediante lo que puede llamarse la "despronominalización" o vaciamiento de toda referencia personal. La ausencia de reconocimiento y solidaridad hace aparecer los deícticos más implicativos, el "yo" y el "tú", desconectados, irreconciliables, lo cual no permite lograr la suma del "nosotros". La consecuencia es el aislamiento, la ausencia, la falta de diálogo... Y la mudez, la indiferencia, la incapacidad para mirarse y reconocerse, si en la mirada está el alma del otro, lo que se busca en él o se le entrega: el alma, la intimidad, el reconocimiento, la solidaria compañía. Puede verse todo esto en poemas como: "El amor en tiempos del despido libre", "Tú y yo tampoco somos nosotros”, “Como si fuera pájaro"... Se lee en el primero de éstos: "Se lamen. No pueden pronunciar / sus nombres. Ni sonreír. / Ni pensar en mañana. / Que es el tuyo o el mío / pero no el de ambos". Y en el segundo: “Vamos en una verdadera calma tú y yo, / pero no nosotros (...) / 
Vamos bien mudos, sorteando zarzas del laberinto. / Así el buey y su enorme ombligo en la propia mano, (...) Y quién es tú, cuando no somos nosotros, / quién la vaca, quién el buey, quién yo? / ¿Son tuyos o son míos esos ojos / que se ven entre los hielos de la pescadería?"

La palabra ausente, la mirada repelida, un camino de abrojos y basuras... rompen la dimensión dialógica del hombre, esa que le reconoce y le vincula a los otros, al mundo, a la historia. Un panorama de seres desperdigados, todo más de animales que se olfatean, debido a un sistema insolidario, competitivo, pone de manifiesto la autora. Pero no menos despersonalizadora y tachadora es la tecnología, que en un poema como "Desaparecemos" convierte al hombre en sombra de sí mismo. Dice en un momento: “Aislados, fuera de horas, sin mover / la lengua ni los pies, con los ojos clavados / en la piedra, / suavemente desaparecemos". ¿Con quién se comunica el hombre, si se han borrado los rostros? ¿A quién ama?

La voz comprometida clamará, a ras de tierra, por la ética que ha enterrado el sistema. Intenta, sin otra arma que la palabra, sacarle los colores recordándole cuanto defeca o arroja por la puerta de atrás mientras continúa la fiesta de la producción y los dígitos desbocados. El cuánto es la pregunta, lo único que importa, la clave que sostiene las vidas anónimas de quienes se han convertido sólo en consumidores o consumidos. Hasta tal punto que la lírica carece de sentido, ha perdido todo lugar. Es lo que hiperboliza en un poema como "Cuánto, lírica palabra".

Para hablar de este mundo desquiciado, para dejar al aire su armazón de óxido, chirriante, sus muñones, la poeta se atreve a desencajar el lenguaje, a hacerle, gramaticalmente, tantas veces saltar hecho añicos. Se vale de preguntas en batería, ardientes y absurdas, de reiteraciones cortadas o latiguillos que cojean, de ambigüedades que supuran la incertidumbre, de anáforas acusadoras, de hipérboles visionarias, de ironías acedas... "Mira, Darwin, cuán cerca del aullido / cae el diccionario / y cómo vuelven al carbón / los restos del brillante", se lee en alguna ocasión, como denuncia de la involución de la especie. Este lenguaje acusador, visionario, sin parapetos -en medio César Vallejo, Gonzalo Rojas, Juan Gelman...- es, 
en su desmesura, en su hermosura desvalida pero arrogante, el lenguaje de la alerta, el de la ferocidad, la tierna ferocidad de la condolencia universal.

Hacer que la lengua hable, que sea expresiva y no retiña, que encuentre el tono, el diapasón ajustado y, así, ilumine, aclare, fije, es de agradecer, porque eso es la poesía, lo que se debe pedir a la poesía. Y es lo que hace en este libro María Ángeles Maeso. Con él comunica e interpela, y fragua la realidad. Opone a la violencia insoslayable de nuestro tiempo, de todo tiempo, una certeza moral, la piedad más humana y la palabra que no se resigna.

César Augusto Ayuso 